\title{
Telmisartan as a peroxisome proliferator-activated receptor- $\gamma$ ligand is a new target in the treatment of human renal cell carcinoma
}

\author{
KIYOAKI FUNAO $^{1}$, MASAHIDE MATSUYAMA ${ }^{1,4}$, YUTAKA KAWAHITO ${ }^{2}$, HAJIME SANO ${ }^{3}$, \\ JAMEL CHARGUI $^{4}$, JEAN-LOUIS TOURAINE ${ }^{4}$, TATSUYA NAKATANI $^{1}$ and RIKIO YOSHIMURA ${ }^{1}$ \\ ${ }^{1}$ Department of Urology, Osaka City University Graduate School of Medicine, 1-4-3 Asahi-machi, Abeno-ku, \\ Osaka 545-8585; ${ }^{2}$ Department of Inflammation and Immunology, Graduate School of Medical Science, \\ Kyoto Prefectural University of Medicine, 465 Kajiicho, Kawara-machi, Kamigyou-ku, Kyoto 602-0841; \\ ${ }^{3}$ Department of Internal Medicine, Hyogo College of Medicine, 1-1 Mukogawa-cho, Nishinomiya, Hyogo 663-8501, \\ Japan; ${ }^{4}$ Department of Transplantation and Clinical Immunology, Claude Bernard University of Lyon \\ and Lyon Hospitals, Pavillion P, Hôpital Edouard Herriot, Lyon Cedex 3, 69437, France
}

Received June 19,2008; Accepted January 7, 2009

DOI: 10.3892/mmr_00000083

\begin{abstract}
Angiotensin II receptor blockers (ARBs) are widely used as hypertensive therapeutic agents. However, it has been reported that Telmisartan (a type of ARB) additionally activates peroxisome proliferator-activated receptor (PPAR) $-\gamma$. We previously reported that PPAR- $\gamma$ ligand induced the growth arrest of renal cell carcinoma (RCC) cells through apoptosis, and that Telmisartan had the potential to inhibit prostate cancer cell growth through apoptosis. In this study, we evaluated the effects of Telmisartan and other ARBs on cell proliferation in an RCC cell line using normal proximal tubular endothelial cells (PRTECs) and the human RCC (Caki-1) cell line. The effects of Telmisartan as well as of other ARBs (Candesartan, Valsartan, Irbesartan and Losartan) on RCC cell growth were examined by MTT assay. Flow cytometry and Hoechst staining were used to determine whether or not the ARBs induced apoptosis. Telmisartan caused marked inhibition in RCC cells in a concentration- and time-dependent manner. Treatment with $100 \mu \mathrm{M}$ of Telmisartan induced early apoptosis and DNA fragmentation in the RCC cells, but not in the PRTECs. None of the other ARBs had an effect on cell proliferation in the RCC cells or the PRTECs. Telmisartan may mediate potent antiproliferative effects against RCC cells through PPAR- $\gamma$. Thus, Telmisartan is a potential target for prevention and treatment in RCC.
\end{abstract}

Correspondence to: Dr Rikio Yoshimura, Department of Urology, Osaka City University Hospital, 1-4-3 Asahi-machi, Abenoku, Osaka 545-8585, Japan

E-mail: jasmin@med.osaka-cu.ac.jp

Key words: Telmisartan, angiotensin II receptor blocker, peroxisome proliferator-activated receptor- $\gamma$, renal cell carcinoma, apoptosis

\section{Introduction}

Recently, with increased routine medical check-ups and progress in diagnostic imaging techniques, there has been an increase in the number of cases of renal cell carcinoma (RCC) diagnosed. However, the causes of RCC remain unknown. Compared to many other types of cancer, RCC generally does not respond well to chemotherapy. Thus, surgery is currently the only therapeutic option.

Angiotensin II (AII) is known as a key biological peptide in the renin-angiotensin system, which regulates blood pressure and renal hemodynamics. AII receptor blockers (ARBs) are widely used as antihypertensive drugs (1). It is well known that angiogenesis is essential for tumor progression and metastasis $(2,3)$. Several studies have demonstrated that AII induces neovascularization and that ARBs inhibit vascular endothelial growth factor (VEGF) production $(4,5)$. Benson et al reported a structural resemblance between Telmisartan (a type of ARB) and Pioglitazone, a peroxisome proliferator-activated receptor (PPAR)- $\gamma$ ligand approved for the treatment of type 2 diabetes. They also reported that Telmisartan has PPAR- $\gamma$ activation action (6).

PPARs are lipid-activated transcriptional factors that function as important regulators of lipid and glucose metabolism, adipocyte differentiation, and energy homeostasis. Several subtypes of PPAR $(\alpha, \beta$ and $\gamma$ ) have been found. PPAR- $\alpha$ and $-\gamma$ mediate the action of hypolipidemic fibrates and antidiabetic thiazolidinediones. PPARs therefore play a role in metabolic conditions such as dyslipidemia and type 2 diabetes, leading to atherosclerosis development (7). They also have a regulatory role in inflammation. PPAR- $\gamma$ provides a strong link between lipid metabolism and the regulation of gene transcription (8), acts in adipose tissue and promotes lipogenesis under anabolic conditions. Recently, the PPAR receptor has also been implicated in inflammation and tumorigenesis. Significant evidence from many experimental systems suggests that PPAR- $\gamma$ plays a key role in carcinogenesis. 
The ligands of PPAR- $\gamma$, which is up-regulated in malignant tissue, induce terminal differentiation in human breast and colon cancer cells $(9,10)$ and inhibit the growth of human lung and gastric cancer cells $(11,12)$. In addition, PPAR- $\gamma$ ligands induce growth arrest through apoptosis in macrophage, fibroblast and endothelial cells $(7,13,14)$.

We have previously reported that Telmisartan has the potential to inhibit the growth of prostate cancer cells through apoptosis (20). Consequently, in the present study we aimed to evaluate the inhibitory effect of Telmisartan on human RCC cells, and to determine whether or not it induces apoptosis in these cells. Our findings elucidate PPAR expression in urological cancer and indicate that the administration of PPAR- $\gamma$ ligand may serve as a form of anticancer therapy (15-19).

\section{Materials and methods}

Reagents and materials. RPMI-1640 was purchased from Nissui Pharmaceutical Co. (Tokyo, Japan). Fetal bovine serum (FBS) and penicillin-streptomycin mixture were from Biowhittaker (Walkersville, MD, USA). Trypsin/EDTA was from Gibco BRL (Rockville, MD, USA). The AII blockers Telmisartan, Candesartan and Irbesartan were from Toronto Research Chemicals Inc. (Canada). The ARB Losartan was from Cayman Chemical (MI, USA).

Cell cultures. The human RCC (Caki-1) cell line and normal proximal tubular endothelial cells (PRTECs) were obtained from the Health Science Research Resources Bank (HSRRB, Osaka, Japan). Cells were grown in culture flasks (Nunc, Roskilde, Denmark) in RPMI-1640 supplemented with $10 \%$ FBS, $100 \mathrm{U} / \mathrm{ml}$ of penicillin and $100 \mu \mathrm{g} / \mathrm{ml}$ of streptomycin in a humidified $5 \% \mathrm{CO}_{2}$ atmosphere at $37^{\circ} \mathrm{C}$. Media were changed every 3 days. When cells reached subconfluence, they were separated via trypsinization using trypsin/EDTA.

Cell-proliferation studies. Cells $\left(\sim 1.0 \times 10^{4}\right)$ were placed onto $8 \times 8 \mathrm{~mm}$ diameter multichamber slides (Nunc) and treated with Telmisartan and other ARBs dissolved in ethanol, with a final ethanol concentration of $<0.05 \%$. Cell viability was measured on day 1 with a microplate reader using a modified 3-[4,5dimethylthiazol-2-thiazolyl]-2,5-diphenyl-tetrazolium bromide (MTT) assay (WST-1 assay; Dojindo, Kumamoto, Japan), and presented as the percentage of control culture conditions.

\section{Flow cytometry}

Annexin $V$ and propidium iodide staining. The effects of Telmisartan and the other ARBs (Candesartan, Valsartan, Irbesartan and Losartan) on the RCC cells and PRTECs were determined by dual staining with Annexin V-FITC and propidium iodide (PI) using the Annexin V-FITC Apoptosis Detection Kit I (BD Biosciences Pharmingen). Annexin V-FITC and PI were added to the cellular suspension according to the manufacturer's instructions, and a sample fluorescence of $1.0 \times 10^{4}$ cells was analyzed by flow cytometry conducted with FACScan (Becton-Dickinson, Germany).

Annexin V-FITC-positive and PI-negative cells were identified as early apoptotic. Annexin V-FITC- and PI-positive cells were identified as late apoptotic or necrotic.
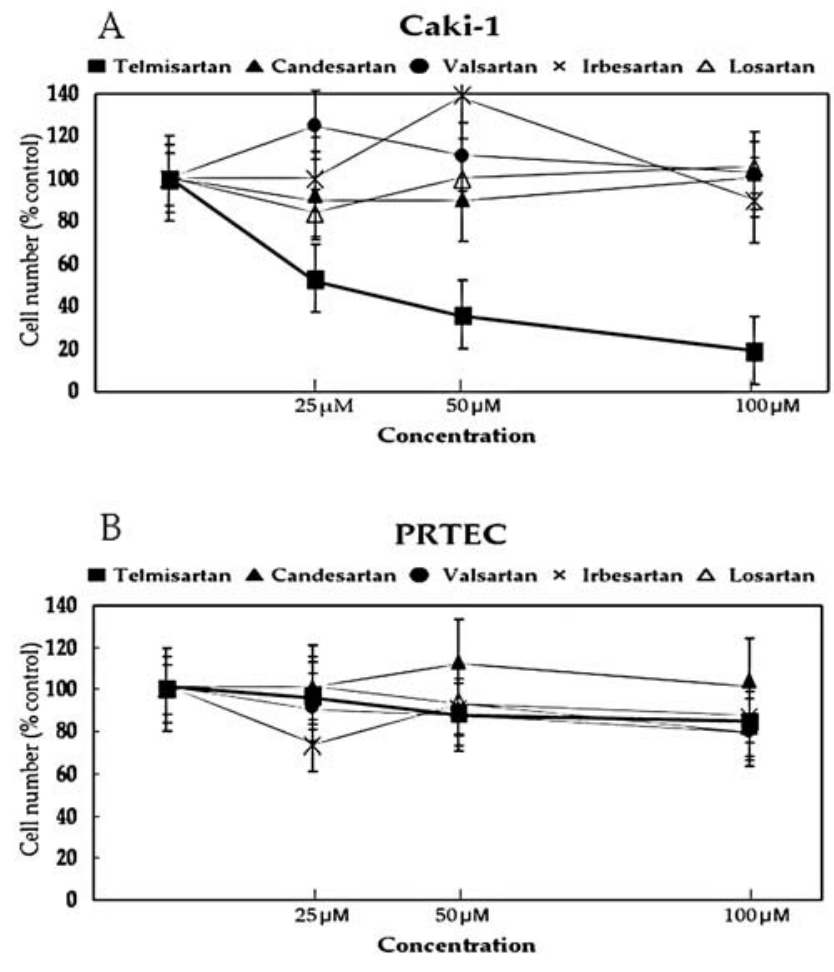

C

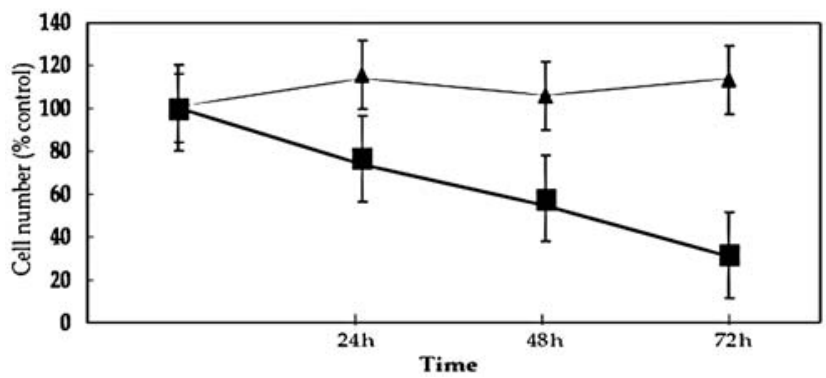

Figure 1. Concentration- and time-dependent effects of Telmisartan. (A) Telmisartan induced a reduction in cell viability with the half-maximal concentration of growth inhibition of RCC cells (range 25-100 $\mu \mathrm{M}$ ), halting RCC cell growth. (B) Telmisartan and other ARBs had no effect on PRTEC proliferation. (C) Cell counts on days 1,2 and 3 clearly indicate that $100 \mu \mathrm{M}$ of Telmisartan markedly inhibited cell proliferation, halting RCC cell growth.

Identification of DNA fragmentation. The assay was performed with the TdT-mediated dUTP nick end-labeling (TUNEL) method using the Apo-Direct ${ }^{\mathrm{TM}}$ kit (Becton-Dickinson). Following the experiments, RCCs and PRTECs were suspended $\left(1 \times 10^{6} / \mathrm{ml}\right)$ and fixed with $1 \%$ PBS, washed in PBS and suspended in $70 \%(\mathrm{v} / \mathrm{v})$ ice-cold ethanol at $-20^{\circ} \mathrm{C}$ until use. The positive and negative controls and the sample were stained with FITC-dUTP by incubation in terminal deoxynucleotidyl transferase buffer as per the manufacturer's instructions, and a sample fluorescence of $1.0 \times 10^{4}$ cells was analyzed by flow cytometry (Becton-Dickinson). Results were expressed as the percentage (\%) of TUNEL-positive cells.

Detection of apoptosis. DNA chromatin morphology was assessed using Hoechst staining. RCCs and PRTECs were incubated with $100 \mu \mathrm{M}$ Telmisartan and other ARBs for $24 \mathrm{~h}$. Cells were washed by RPMI-1640 and labeled with $8 \mathrm{mg} / \mathrm{ml}$ of Hoechst 33342 (Sigma-Aldrich Japan K.K., Tokyo, Japan) 
A

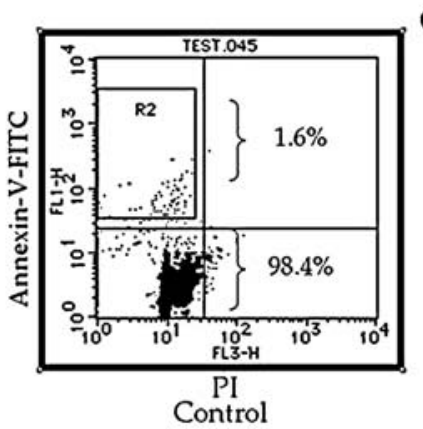

Caki-1
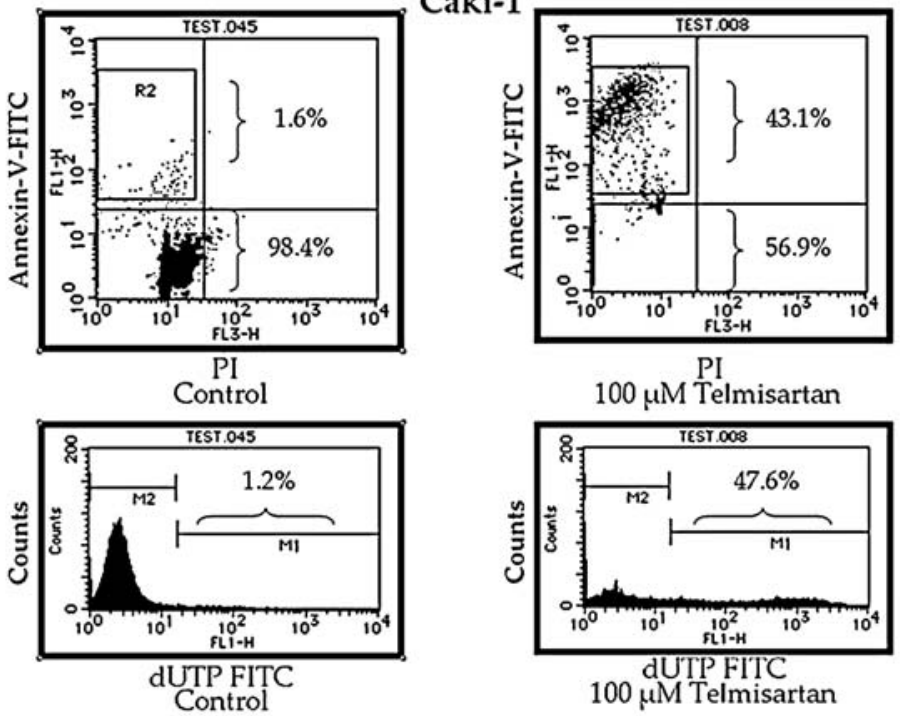

$100 \mu \mathrm{M}$ Telmisartan
B

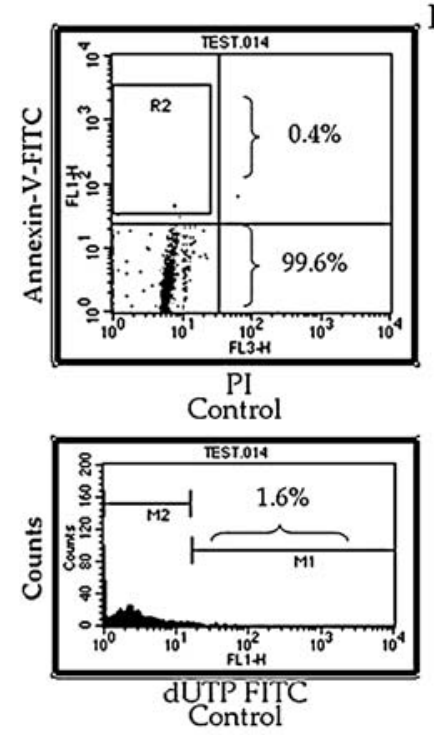

PRTEC

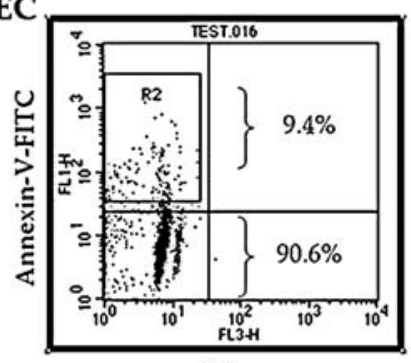

$100 \mu \mathrm{M}$ Telmisartan

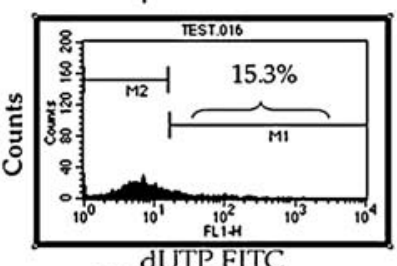

$100 \mu \mathrm{M}$ Telmisartan

Figure 2. The effects of Telmisartan on early and late apoptosis by flow cytometry. (A) Treatment with $100 \mu \mathrm{M}$ Telmisartan induced early apoptosis in almost the total percentage of RCC cells. (B) Treatment with $100 \mu \mathrm{M}$ Telmisartan induced neither apoptosis nor DNA fragmentation in normal proximal tubular endothelial cells (PRTECs). Representative FITC-Annexin V/PI flow cytometry diagrams are shown, indicating that $100 \mu \mathrm{M}$ of Telmisartan induced DNA fragmentation in RCC cells. Representative flow cytometry histograms are also shown. The top left quadrants represent early apoptosis (Annexin V-FITC-positive and PI-negative cells). The top right quadrants represent late apoptosis and necrosis (Annexin V-FITC- and PI-positive cells).

for 10 min. PI (Sigma-Aldrich Japan K.K.) was added for a final concentration of $10 \mathrm{mg} / \mathrm{ml}$, and the cells were examined by fluorescence microscopy.

\section{Results}

Telmisartan-induced growth inhibition in RCCcells by MTT. To investigate the effects of Telmisartan and other ARBs on RCC cell proliferation, we analyzed cell viability in vitro using the MTT assay. As shown in Fig. 1A, Telmisartan induced a reduction in cell viability with the half-maximal concentration of growth inhibition of RCC cells (range 25-100 $\mu \mathrm{M}$ ). However, Telmisartan and the other ARBs had no effect on PRTEC proliferation (Fig. 1B). Furthermore, cell counts on days 1, 2 and 3 clearly indicate a marked inhibition of cell proliferation with $100 \mu \mathrm{M}$ of Telmisartan (Fig. 1C). Telmisartan therefore halted the growth of RCC cells.

Telmisartan-induced apoptosis by flow cytometry. Flow cytometry was used to evaluate whether cell death induced by Telmisartan and the other ARBs was achieved through apoptosis. As shown in Fig. 2, treatment with $100 \mu \mathrm{M}$ of Telmisartan induced early apoptosis in almost the total percentage of RCC cells (Fig. 2A), while treatment with the same amount of Telmisartan antagonist in PRTECs had no effect (Fig. 2B). 

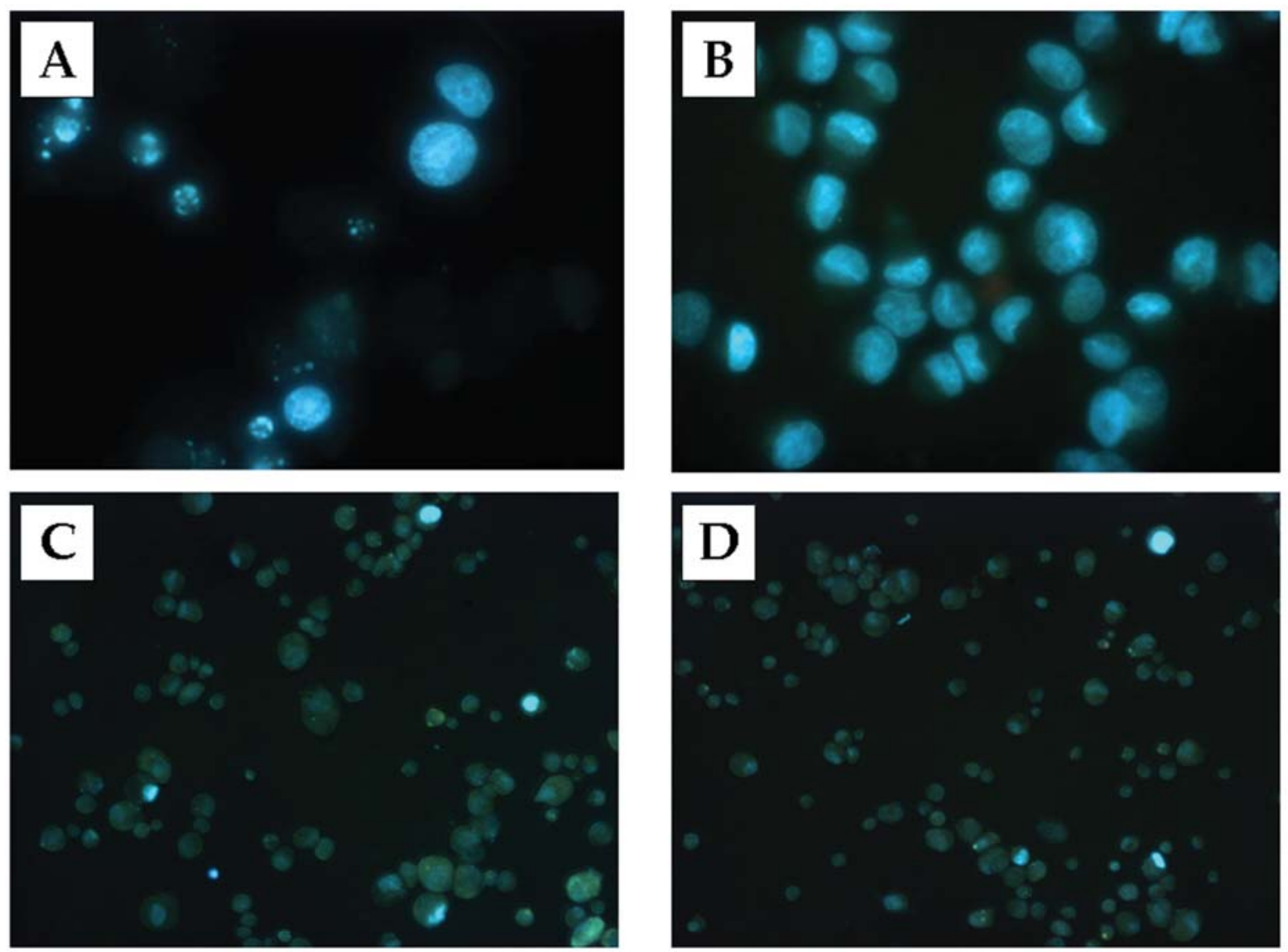

Figure 3. The effects of Telmisartan on the induction of apoptosis in RCC cells. (A) RCC cells treated with Telmisartan exhibited significant chromatin condensation, cellular shrinkage, small membrane-bound (apoptotic) bodies and cytoplasmic condensation. These cellular changes were typically redundant characteristics of apoptosis. (B) Untreated RCC cells maintained normal chromatin patterns and cell size. (C) PRTECs treated with Telmisartan did not exhibit significant chromatin condensation, cellular shrinkage, small membrane-bound (apoptotic) bodies or cytoplasmic condensation. (D) Untreated PRTECs maintained normal chromatin patterns and cell size.

Additionally, treatment with $100 \mu \mathrm{M}$ Telmisartan induced DNA fragmentation in the RCC cells (Fig. 2A), but not in the PRTECs (Fig. 2B). The other ARBs did not induce DNA fragmentation in the RCCs or PRTECs (data not shown).

Effect of Telmisartan on the induction of apoptosis in RCC cells. To evaluate whether or not cell death induced by Telmisartan was caused by apoptosis, we evaluated the chromatin morphology of RCC cells and PRTECs using Hoechst staining. RCCs treated with Telmisartan exhibited significant chromatin condensation, cellular shrinkage, small membranebound (apoptotic) bodies and cytoplasmic condensation. These cellular changes were typically redundant characteristics of apoptosis (Fig. 3A). Untreated RCC cell lines maintained normal chromatin patterns and cell size (Fig. 3B).

On the other hand, PRTECs treated with Telmisartan did not exhibit significant chromatin condensation, cellular shrinkage, small membrane-bound bodies (apoptotic bodies) or cytoplasmic condensation (Fig. 3C). Untreated PRTECs maintained normal chromatin patterns and cell size (Fig. 3D).

Furthermore, RCC cells and PRTECs treated with other ARBs did not exhibit significant chromatin condensation, cellular shrinkage, small membrane-bound (apoptotic) bodies or cytoplasmic condensation (data not shown).

\section{Discussion}

Anticancer and antiangiogenetic effects of angiotensin II receptor blockers. ARBs have been synthesized and available for the treatment of hypertension since the 1990s $(21,22)$. AII has been known to promote tumor growth and angiogenesis, while ARBs have been considered a noteworthy anticancer and antiangiogenetic therapeutic option (23).

In previous years, some tumor cells, such as melanoma, pancreatic cancer $(24)$, renal cancer $(25,26)$, breast cancer $(27)$, bladder tumor (28) and prostate cancer (29), were reported to express the AII receptor $(24,25,28-31)$. Several studies have investigated the antitumor effect of ARBs throughout antiangiogenesis. Kosugi et al reported that Candesartan (an $\mathrm{ARB}$ ) prevented the pulmonary metastasis of renal cancer and bladder tumors by inhibiting tumor angiogenesis through the suppression of VEGF in a xenograft model (28). In prostate cancer, some investigators reported that Candesartan inhibited the production of VEGF, one of the most potent and specific angiogenic factors, and decreased the prostate cancer $(29,32)$. Kosaka et al reported that a specific ARB suppressed VEGF production, resulting in reduced tumor angiogenesis and a slower progression of prostate cancer in a tumor xenograft model (29). Uemura et al reported that the clinical use of 
Candesartan in prostate cancer patients with hypertension resulted in a reduction of prostate-specific antigen, while patient performance status improved (32). However, they also reported that Candesartan had no effect on tumor growth in vitro, and did not detect apoptosis. Based on their in vitro and in vivo experiments, they suggested that the antitumor effect of ARB was not due to direct toxicity or apoptotic induction, but was rather an antiangiogenetic effect $(28,29)$.

The results of the present study indicate that Candesartan and other ARBs (with the exception of Telmisartan) did not induce a reduction in cell viability and early apoptosis in RCC cells. Telmisartan alone induced a reduction in cell viability, with a half-maximal concentration of growth inhibition, early apoptosis and the DNA fragmentation of the RCC cells.

Telmisartan is a partial agonist of peroxisome proliferatoractivated receptor $-\gamma$. Benson et al reported a structural resemblance between Telmisartan and Pioglitazone, a PPAR- $\gamma$ ligand approved for the treatment of type 2 diabetes. They found that Telmisartan blocks the AII receptor, activating PPAR $-\gamma$. Telmisartan functioned as a moderately potent selective PPAR- $\gamma$ and also as a partial agonist, activating the receptor to $25-30 \%$ of the maximum level achieved by the full agonists pioglitazon and resiglitazone (6).

Anticancer effects of peroxisome proliferator-activated receptor- $\gamma$. PPARs are members of the nuclear receptor superfamily of ligand-activated transcriptional factors, such as steroids, thyroid hormone, vitamin $\mathrm{D}_{3}$ and retinoic acid. PPAR binds to the peroxisome proliferator response element as a heterodimer with the retinoic receptor in the regulation of PPAR target genes. PPARs are considered to be important immunomodulatory factors, as well as fatty acid regulators. They modulate these activities in different immune cell types, such as monocytes/macrophages, lymphocytes and endothelial cells (33).

PPAR $-\gamma$ is expressed at high levels in adipose tissue, where it acts as a critical regulator of adipocyte differentiation. It is also expressed in the immune system, the spleen, monocyte bone-marrow precursors and helper T-cell clones, as well as in chondrocytes, synovial and bone tissues. Recent data indicate that the PPAR- $\gamma$ ligand leads to the inhibition of phorbol ester-induced nitric oxide and macrophage-derived cytokines, such as tumor necrosis factor- $\alpha$, interleukin- $1 \beta$ and -6 , chemokines, and adhesion molecules. It accomplishes this inhibition in part by antagonizing the activities of transcriptional factors (11). Thiazolidinedione, a new class of antidiabetic acting as a specific ligand for PPAR $-\gamma$, and retinoic receptor agonists, have been evidenced to regulate the differentiation of cancer cells (34). Moreover, nuclear-acting prostanoids, including 15 -deoxy- $\Delta^{12,14}$-prostaglandin $\mathrm{J}_{2}$ (15-d$\mathrm{PGJ}_{2}$ ), are potent activators of the PPAR- $\gamma$ receptor isoform $(35,36)$. 15-Deoxy- $\Delta^{12,14}$-prostaglandin $\mathrm{J}_{2}$ induces apoptosis in macrophages, endothelial cells and choriocarcinoma cells $(7,14,37)$, as well as thiazolidinedione-induced fibroblast apoptosis (8).

We previously reported that PPAR- $\gamma$ was strongly expressed in RCC tissues. The extent and intensity of PPAR- $\gamma$ expression was greater in normal kidney tissues than in RCC tissues. PPAR- $\gamma$ expression was also stronger in high-grade than in low-grade carcinoma. PPAR- $\gamma$ ligand strongly induced early apoptosis in RCC cells, as indicated by flow cytometry and Hoechst staining (15). In this study, only Telmisartan had a direct toxicity throughout apoptosis. Thus, it may mediate potent antiproliferative effects against RCC cells through PPAR $-\gamma$. However, the dose required for this effect was not clinically achievable in the current study. Further studies are needed to extend the application of Telmisartan to a clinical trial of treatment for RCC.

\section{Acknowledgements}

This study was edited by Hilah Edney, BSc, MSc.

\section{References}

1. See S and Stirling AL: Candesartan cilexetil: an angiotensin IIreceptor blocker. Am J Health Syst Pharm 57: 739-746, 2000

2. Folkman J: Tumor angiogenesis: therapeutic implications. N Engl J Med 285: 1182-1186, 1971.

3. Folkman J: Angiogenesis in cancer, vascular, rheumatoid and other disease. Nat Med 1: 27-31, 1995.

4. Le Noble FA, Hekking JW, van Straaten HW, Slaaf DW and Struyker Boudier HA: Angiotensin II stimulates angiogenesis in the chorio-allantoic membrane of the chick embryo. Eur J Pharmacol 195: 305-306, 1991.

5. Le Noble FA, Schreurs NH, van Straaten HW, et al: Evidence for a novel angiotensin II receptor involved in angiogenesis in chick embryo chorioal-lantoic membrane. Am J Physiol 264: 460-465, 1993.

6. Benson SC, Pershadsingh HA, Ho CI et al: Identification of Telmisartan as a unique angiotensin II receptor antagonist with selective PPAR $\gamma$-modulating activity. Hypertension 43: 993-1002, 2004.

7. Chinetti G, Griglio S, Antonucci M, et al: Activation of proliferator-activated receptors alpha and gamma induces apoptosis of human monocyte-derived macrophages. J Biol Chem 273: 25573-25580, 1998.

8. Spiegelman BM: PPAR-gamma: adipogenic regulator and thiazolidinedione receptor. Diabetes 47: 507-514, 1998.

9. Mueller E, Sarraf P, Tontonoz P, et al: Terminal differentiation of human breast cancer through PPAR gamma. Mol Cell 1: 465-470, 1998.

10. Sarraf P, Mueller E, Jones D, et al: Differentiation and reversal of malignant changes in colon cancer through PPAR-gamma. Nat Med 4: 1046-1052, 1998.

11. Tsubouchi Y, Sano H, Kawahito Y, et al: Inhibition of human lung cancer cell growth by the peroxisome proliferator-activated receptor $-\gamma$ agonists through induction of apoptosis. Biochem Biophys Res Commun 270: 400-405, 2000.

12. Takahashi N, Okumura T, Motomura W, Fujimoto Y, Kawabata I and Kohgo Y: Activation of PPAR gamma inhibits cell growth and induces apoptosis in human gastric cancer cells. FEBS Lett 455: 135-139, 1999.

13. Altiok S, Xu M and Spiegelman BM: PPARgamma induces cell cycle withdrawal: inhibition of E2F/DP DNA-binding activity via down-regulation of PP2A. Genes Dev 11: 1987-1998, 1997.

14. Bishop-Bailey D and Hla T: Endothelial cell apoptosis induced by the peroxisome proliferator-activated receptor (PPAR) ligand 15-deoxy-Delta12,14-prostaglandin J2. J Biol Chem 274: 17042-17048, 1999.

15. Inoue K, Kawahito Y, Tsubouchi Y, et al: Expression of peroxisome proliferator-activated receptor gamma in renal cell carcinoma and growth inhibition by its agonists. Biochem Biophys Res Commun 287: 727-732, 2001.

16. Yoshimura R, Matsuyama M, Segawa Y, et al: Expression of peroxisome proliferator-activated receptors (PPARs) in human urinary bladder carcinoma and growth inhibition by its agonists. Int J Cancer 104: 597-602, 2003.

17. Segawa Y, Yoshimura R, Hase T, et al: Expression of peroxisome proliferator-activated receptor (PPAR) in human prostate cancer. Prostate 51: 108-116, 2002.

18. Hase T, Yoshimura R, Mitsuhashi M, et al: Expression of peroxisome proliferator-activated receptors in human testicular cancer and growth inhibition by its agonists. Urology 60: 542-547, 2002. 
19. Yoshimura R, Matsuyama M, Hase T, et al: The effect of peroxisome proliferator-activated receptor-gamma ligand on urological cancer cells. Int J Mol Med 12: 861-865, 2003.

20. Funao K, Matsuyama M, Kawahito Y, et al: Telmisartan is a potent target for prevention and treatment in human prostate cancer. Oncol Rep (In press).

21. Burnier M: Angiotensin II type 1 receptor blockers. Circulation 103: 904-912, 2001

22. Dina R and Jafari M: Angiotensin II-receptor antagonists. Am J Health Syst Pharm 57: 1231-1241, 2000.

23. Abali H, Güllü H, Engin H, Haznedaroglu C, Erman M and Tekuzman G: Old antihypertensive as novel antineoplastics: angiotensin-I-converting enzyme inhibitors and angiotensin II type 1 receptor antagonists. Med Hypotheses 59: 344-348, 2002.

24. Fujimoto Y, Sasaki T, Tsuchida A and Chayama K: Angiotensin II type 1 receptor expression in human pancreatic cancer and growth inhibition by angiotensin II type 1 receptor antagonist. FEBS Lett 495: 197-200, 2001.

25. Miyajima A, Kosaka T, Asano T, et al: Angiotensin II type 1 antagonist prevents pulmonary metastasis of murine renal cancer by inhibiting tumor angiogenesis. Cancer Res 62: 4176-4179, 2002.

26. Goldfarb DA, Diz DI, Tubbs RR, Ferrario CM and Novick AC: Angiotensin II receptor subtypes in the human renal cortex and renal cell carcinoma. J Urol 151: 208-213, 1994.

27. Inwang ER, Puddefoot JR, Brown CL, et al: Angiotensin II type 1 receptor expression in human breast tissues. Br J Cancer 75 1279-1283, 1997.

28. Kosugi M, Miyajima A, Kikuchi E, Horiguchi Y and Murai M Angiotensin II type 1 receptor antagonist candesartan as an angiogenic inhibitor in a xenograft model of bladder cancer. Clin Cancer Res 12: 2888-2893, 2006.
29. Kosaka T, Miyajima A, Takayama E, et al: Angiotensin II type I receptor antagonist as an angiogenic inhibitor in prostate cancer. Prostate 67: 41-49, 2007.

30. Egami K, Murohara T, Shimada T, et al: Role of host angiotensin II type 1 receptor in tumor angiogenesis and growth. J Clin Invest 112: 67-75, 2003.

31. Koh WP, Yuan JM, van den Berg D, Lee HP and Yu MC: Polymorphisms in angiotensin II type 1 receptor and angiotensin Iconverting enzyme genes and breast cancer risk among Chinese women in Singapore. Carcinogenesis 26: 459-464, 2005.

32. Uemura H, Hasumi H, Kawahara $\mathrm{T}$, et al: Pilot study of angiotensin II receptor blocker in advanced hormone-refractory prostate cancer. Int J Clin Oncol 10: 405-410, 2005.

33. Kawahito Y, Kondo M, Tsubouchi Y, et al: 15-Deoxy-delta $(12,14)-P G J(2)$ induces synoviocyte apoptosis and suppresses adjuvant-induced arthritis in rats. J Clin Invest 106: 189-197, 2000.

34. Dreyer C, Krey G, Keller H, Givel F, Helftenbein G and Wahli W: Control of the peroxisomal beta-oxidation pathway by a novel family of nuclear hormone receptors. Cell 68: 879-887, 1992.

35. Kliewer SA, Umesono K, Noonan DJ, Heyman RA and Evans EM: Convergence of 9-cis retinoic acid and peroxisome proliferator signalling pathways through heterodimer formation of their receptors. Nature 358: 771-774, 1992.

36. Kliewer SA, Forman BM, Blumberg B, et al: Differential expression and activation of a family of murine peroxisome proliferator-activated receptors. Proc Natl Acad Sci USA 91: 7355-7359, 1994.

37. Keelan JA, Sato TA, Marvin KW, Lander J, Gilmour RS and Mitchell MD: 15-Deoxy-Delta (12, 14)-prostaglandin J (2), a ligand for peroxisome proliferator-activated receptor-gamma, induces apoptosis in JEG3 choriocarcinoma cells. Biochem Biophys Res Commun 262: 579-585, 1999. 